\title{
Na lembrança, tudo é fecundo, tudo é perigoso
}

Graciela Deri de Codina, UPM-SP

À minha querida Jeanne Marie, irmã e mestre.

Resumo: O estudo consiste na análise do sentido da escrita no romance de Proust, Em busca do tempo perdido, a partir do relato sobre a vocação, incluído no enredo do romance. Apresenta a dúvida a respeito do significado da literatura no contexto da discussão sobre o realismo, o que implica na questão da memória como indispensável para entender a complexa relação entre a materialidade da vida e a obra.

Palavras-chave: literatura; lembrança; vida.

Nossa investigação está situada na complexa fronteira entre filosofia e literatura, o que nos coloca no cerne de uma discussão estética sobre o significado da obra de arte. Pretendemos refletir a respeito do sentido do romance de Proust, Em busca do tempo perdido, como problematização da vocação literária incluída, não por acaso, no enredo da narrativa. Para explicitar esse problema, é necessário analisar, ao longo do percurso da própria narrativa, a descrição da desilusão como aprendizagem da "verdade" que consiste, concomitantemente, no sentido da vida e da obra, descoberta da vocação como resposta problemática que se renova na circulação de sentido no romance. Nele encontramos inúmeras expressões que ilustram a conclusão do autor: "La grandeur de l'art véritable [...]", "La vraie vie [...] c'est la littérature.", , "[...] la vérité suprême de la vie est dans l'art [...]".

Pode-se entrever a problemática de uma vocação singular que é mediação para a construção de uma experiência universalizante. A universalidade atingida pressupõe um longo caminho, a própria narrativa, a ser percorrido como desilusão, como dilaceramento do eu que, no limite, conduz à impossibilidade da coincidência do sujeito consigo mesmo. No entanto, esse resultado foi construído na expressão da obra de arte como outra dimensão que salva da desilusão provocada pelo esfacelamento do sujeito no tempo, o espaço da narrativa constitui a possibilidade de uma espécie de eternidade encontrada e apresentada no último volume da Recherche. ${ }^{3}$ Neste contexto, o presente estudo visa mostrar e problematizar o movimento entre a procura de um sentido permanentemente adiado e somente encontrado no final da obra, e a sua descoberta que, paradoxalmente, já estava lá desde o começo da escrita.

\section{À procura do verdadeiro sentido da obra}

O movimento de desilusão e descoberta de sentido repete-se em várias tentativas de escrever desde o primeiro volume, no qual já aparecem as primeiras experiências da escrita, em várias passagens, o herói constata o "désaccord entre nos impressions et leur expression habituelle."4 A tentativa de dizer as impressões é sempre muito difícil:

Cadernos Benjaminianos, Número especial, Belo Horizonte, 2013, página 100-114 100 
Et voyant sur l'eau et à la face du mur un pâle sourire répondre au sourire du ciel, je m'écriai dans mon enthousiasme en brandissant mon parapluie refermé: “Zut, zut, zut, zut." Mais en même temps je sentis que mon devoir eût été de ne pas m'en tenir à ces mots opaques et de tâcher de voir plus clair dans mon ravissement. ${ }^{5}$

O entusiasmo, o encantamento com a impressão se transforma em frustração, o prazer que o menino experimentava no contato com a natureza carregava também a necessidade de ultrapassá-lo para atingir algo mais do que palavras opacas, alguma coisa oculta no que via: "[...] quelque chose qu'ils invitaient à venir prendre et que malgré mes efforts je n'arrivais pas à découvrir." " Apresenta-se, dessa perspectiva, a dor sentida pela impossibilidade de ir além dessa sensação e penetrar no sentido do prazer que proporcionava uma "impressão de fecundidade", 7 mas sempre aliado a um sentimento de impotência que o invadia quando procurava o assunto de sua obra sempre adiada.

Todavia, pouco depois dessa infrutífera tentativa de descoberta, o narrador, por uma espécie de antecipação de sentido, apresenta o herói num lampejo de inspiração que o obriga a escrever em resposta a esse entusiasmo, experiência da qual ele não tem consciência, mas que o torna extremamente feliz:

Sans me dire que ce qui était caché derrière les clochers de Martinville devait être quelque chose d'analogue à une jolie frase, puisque c'était sous la forme de mots que me faisaient plaisir, que cela m'était apparu, demandant un crayon et du papier au docteur, je composai malgré les cahots de la voiture, pour soulager ma conscience et obéir à mon enthousiasme, le petit morceau suivant $[\ldots] .^{8}$

Reencontramos o mesmo movimento no último volume, nos sentimentos contraditórios que a leitura dos Goncourt proporciona. Por um lado, o herói constata com tristeza que, ao contrário do que havia julgado durante grande parte de sua vida, a literatura não revela nenhuma "verdade profunda". ${ }^{9}$ Essa constatação o consola do confinamento numa casa de saúde, já que a beleza relatada nos livros não se distingue do que ele tinha visto, portanto, apresenta-se a decepção com a realidade e a impossibilidade de descobrir o que se esconde atrás dela.

Por outro lado, um sentimento contraditório o assalta, uma inquietação o perturba: essas criaturas descritas pelo diário dos Goncourt eram vulgares, insossas, enfim, desprovidas de qualquer encanto, portanto, incapazes de suscitarem qualquer admiração, mas agora que o diário as mencionava, desejaria revê-las. Esse desejo poderia ser interpretado ironicamente como o prestígio de "[...] une magie illusoire de la littérature, $[\ldots]$ ce côté mesonger, ce faux-jour [...]". "No entanto, as pessoas mais representativas de uma época ou de um grupo, que se nos apresentam tão interessantes na visão do artista, não são as mesmas que parecem instigantes na vida cotidiana. Nesse sentido, a comparação com a pintura é inevitável, já que os retratos mais significativos não constituem aqueles encomendados para a posteridade, que podem até ter um interesse histórico documental, mas aqueles em que o artista manifesta suas impressões, construindo assim outra espécie de verdade. Poderíamos nos perguntar: em que consiste essa "verité d'art"?

Cadernos Benjaminianos, Número especial, Belo Horizonte, 2013, página 100-114 
É relevante considerar que neste mesmo contexto serão retomadas, no último volume, as dúvidas sobre o talento para a literatura colocadas no primeiro, mas agora em um outro patamar de compreensão. O herói reflete a respeito de sua incapacidade de percepção; comparando-se com os Goncourt, ele não sabia ouvir nem olhar. No entanto, de maneira intermitente, aparecia nele uma personagem que se interessava pelo que ouvia e olhava quando observava com prazer essências comuns a vários seres ou situações, o que poderia ser denominado "conjunto de leis psicológicas", ${ }^{12}$ nas quais o importante não é a vulgaridade ou o encanto, mas como essas características apresentam um caráter revelador comum aos diferentes seres.

Si j'avais compris jadis que ce n'est pas le plus spirituel, le plus instruit, le mieux relationné des hommes, mais celui qui sait devenir miroir et peut refléter ainsi sa vie, fût-elle médiocre, qui devient un Bergotte [...], on pouvait à plus forte raison en dire autant des modèles de l'artiste. ${ }^{13}$

Retomaremos mais adiante a questão de se tornar espelho, a necessidade de refletir a vida no estilo que não é somente uma questão de técnica, mas de visão, portanto, a expressão de impressões que precisam ser traduzidas.

O que parece mais interessante nesse momento é a retomada do nome de Bergotte (a personagem do escritor no romance), carregado de significação como modelo de literatura na infância, o que nos conduz novamente ao primeiro volume, no qual se desenvolvem leituras que constituem todo um mundo de descobertas, um mundo paralelo na estadia de férias em Combray (o paraíso perdido da infância), mas tão intenso quanto os passeios que produzem as impressões. Instiga-nos, nessas idas e vindas do último ao primeiro volume, como a narrativa elabora os tempos cruzados.

No primeiro volume, temos vários momentos que poderiam estar no final porque denotam a narrativa de alguém que está contando de um tempo muito posterior e que revive a dor e a realidade como se o tempo não tivesse transcorrido. Há duas passagens extremamente comoventes nesse sentido, nas quais o leitor tem a impressão de que o tempo em que aquilo foi vivido é muito longínquo e, concomitantemente, é presente. Ambas as passagens encontram-se no contexto da leitura e da escrita em Combray; o primeiro aparece logo após o texto sobre os campanários, o segundo, no famoso trecho em que o herói se desespera pela impossibilidade do beijo de boa noite de sua mãe e que culmina com a capitulação desta, que passará a noite lendo um romance para sossegar os nervos do menino. Essa cena, sobejamente comentada por todas as interpretações da obra de Proust, é considerada por muitos intérpretes como o modelo do desejo que constituirá a procura insaciável do amor materno em todos os amores, bem como parcialmente responsável pelo desvio sublimatório em direção à literatura.

Mais c'est surtout comme à des gisements profonds de mon sol mental, comme aux terrains résistants sur lesquels je m'appuie encore, que je dois penser au côté de Méséglise et au côté de Guermantes. C'est parce que je croyais aux choses, aux êtres, tandis que je les parcourais, que les choses, les êtres qu'ils m'ont fait connaître, sont les seuls que je prenne encore au sérieux et qui me donnent encore de la joie. Soit que la foi qui crée soit tarie en moi, soit que la réalité ne se forme que dans la mémoire, les fleurs qu'on me montre aujourd'hui pour la première fois ne me semblent pas de vraies fleurs. ${ }^{14}$

Cadernos Benjaminianos, Número especial, Belo Horizonte, 2013, página 100-114 102 
La possibilité de telles heures ne renaîtra jamais pour moi. Mais depuis peu de temps, je recommence à très bien percevoir si je prête l'oreille, les sanglots que j'eus la force de contenir devant mon père et qui n'éclatèrent que quand je me retrouvai seul avec maman. En réalité ils n'ont jamais cessé; et c'est seulement parce que la vie se tait maintenant davantage autour de moi que je les entends de nouveau, comme ces cloches de couvents que couvrent si bien les bruits de la ville pendant le jour qu'on les croirait arrêtés mais qui se remettent à sonner dans le silence du soir. ${ }^{15}$

Nos dois trechos, parece haver uma conciliação entre o passado e o presente num outro tempo da narração que atravessa as distâncias de modo a propiciar uma realidade que se apresenta como intemporal, visto que constitui a única realidade que fundamenta o solo onde o eu se apóia, permeando a totalidade da vida. Lendo atenciosamente os contextos, percebe-se o quanto a cena da necessidade do beijo da mãe em Combray permanece como modelo, configurando uma sensibilidade que, paradoxalmente, não é possível resgatar, mas, concomitantemente, constitui a única verdade possível.

No caso do primeiro trecho, os caminhos estão associados a uma atividade intelectual forçada pelas peripécias que tornavam possível a satisfação do beijo ou a angústia de sua impossibilidade, considerando que o herói afirma ter aprendido a distinguir seus estados de alma na sucessão dos dias e seus caminhos, cada um apresentando circunstancialidades próprias, que conduziam seu universo anímico em função do desejo do beijo, nem sempre satisfeito. No caso do segundo trecho, é a própria cena que aparece com toda a carga de angústia jamais superada, mas que, muitos anos depois, percebe-se e escuta-se melhor, apresentando toda a sua dimensão trágica.

As possibilidades abertas pelo próprio texto parecem insuficientes, a saber: a) porque a fé na realidade de então foi desmentida pela vivência das desilusões ao longo dos anos, propiciando a irrealidade de tudo o que se pensou ter vivido e, portanto, tornando verdadeiros somente os momentos da infância em que a crença foi possível; b) ou porque a realidade somente pode ser encontrada pela memória. Ambas as possibilidades são necessárias, mas insuficientes, porque não bastam para configurar o sentido retrospectivo que atingem; tanto a vivência da desilusão quanto a experiência da memória somente adquirem significação pela longa elaboração da escrita que constitui a obra.

O contexto esclarece a esse respeito, uma vez que no primeiro trecho acontece uma reflexão sobre o esforço intelectual que as intensas experiências em Combray o obrigavam a desenvolver, e no segundo apresenta-se diretamente uma experiência sobre o prazer da leitura, que é o outro lado significativo da infância. Em ambos encontramos uma verdade que somente a literatura poderia fornecer: a necessidade e o prazer de ler e escrever, na nossa interpretação, os verdadeiros caminhos de Combray, portanto, os caminhos que configuram uma outra realidade que somente pode ser reencontrada pela narração, ou, em termos mais amplos, a realidade que abre os mundos dos artistas na elaboração de suas experiências e na qual o leitor encontra a possibilidade de reencontrar as suas próprias.

Gagnebin, comentando a famosa passagem da madeleine, nos adverte a respeito de uma interpretação simplista que reduziria a obra de Proust a momentos privilegiados da memória involuntária:

Cadernos Benjaminianos, Número especial, Belo Horizonte, 2013, página 100-114 103 
[...] não é a sensação em si (o gosto da madeleine e a alegria por ele provocado) que determina o processo da escrita verdadeira, mas sim a elaboração da sensação, a busca espiritual do seu nome originário, portanto, a transformação, pelo trabalho da criação artística, da sensação em linguagem, da sensação em sentido. ${ }^{16}$

Configura-se assim a verdade artística, descobre-se no tempo, mas, concomitantemente, percebe-se que já estava lá desde seu início sendo, portanto, intemporal. Como demonstra Gagnebin, se a grande descoberta da Recherche fosse somente a dos momentos da memória involuntária, os momentos privilegiados em que os tempos se tornam um só, em estado puro, não haveria necessidade de escrever esse longo romance, a questão já estaria resolvida na passagem em que é descrita a infinita alegria de reencontrar Combray no sabor da madeleine com o chá de tília. No entanto, se retomarmos o começo, percebemos que a questão é muito mais complexa, há uma luta espiritual que se desenvolve como tentativa de pensar a própria experiência, luta que não reflete a problematicidade da materialidade que a propicia, mas que conduz a uma volta para o espírito que vai empreender a tarefa de construir o seu sentido.

Como começa o romance? Alguém, não sabemos quem, começa a falar a partir de não sabemos onde nem quando, como se escolhesse, não por acaso, uma experiência entre o sonho e a vigília que inicia o questionamento a respeito da realidade do tempo e do espaço. O eu que narra também é apresentado como desconhecido para si mesmo, na medida em que se pergunta a respeito do lugar, das horas, etc., é um eu múltiplo e confuso. Essa indecisão a respeito da realidade do tempo e do espaço é constantemente retomada ao longo da obra, apresentada como uma forma de elaboração das impressões e sentimentos que constituem o substrato desse eu tentando encontrar o sentido originário das experiências.

\section{A descoberta do estilo}

No contexto apresentado, é preciso retomar a questão da vocação na dificuldade de sua delimitação. Em primeiro lugar, o tipo de visão que vai constituir o estilo, em segundo lugar, a compreensão de que a falta de talento foi um equívoco.

No momento da leitura do diário dos Goncourt, o herói descobre que seu tipo de percepção do mundo difere dos memorialistas em questão. As características do tipo diferente de percepção podem ser resumidas da seguinte maneira: a) só se interessava quando a diversidade de pessoas ou situações podia apresentar uma "essência geral" comum; ${ }^{17}$ b) a observação, por se situar além da aparência, procurava por um substrato mais profundo, portanto, não se trata de ouvir o que dizem as personagens, mas como o dizem, não é um simples observar, mas um "radiografar" tentando vislumbrar algo além dele. Se tomarmos como exemplo a mesma cena do jantar dos Verdurin, a observação que fascina está na identidade do salão em espaços e tempos diferentes ou no "conjunto de leis psicológicas" 18 que a radiografia dos convivas poderia propiciar. Como foi dito, neste momento, a leitura que lhe proporcionava prazer e provocava o desejo de rever as pessoas, o conduz a uma reflexão sobre a mentira da literatura, mas, de forma ambivalente, à suspeita de uma contra-verdade artística que poderia alcançar através de sua forma de percepção, por enquanto somente intuída.

Cadernos Benjaminianos, Número especial, Belo Horizonte, 2013, página 100-114 104 
Dessa perspectiva, é interessante observar que a narrativa continua, no último volume, com a introdução "realista" da primeira guerra mundial. A descrição de Paris em guerra ilustra a discussão sobre a pretensa "verdade" ou "realidade" da literatura e provoca reflexões que nos auxiliam a compreender o estilo.

Em primeiro lugar, a descrição da guerra aparece ao leitor como extemporânea. Com efeito, num romance em que os acontecimentos históricos não assumem papel de protagonistas, estranha-nos profundamente uma descrição tão detalhada desse momento, só comparável ao espaço dado ao caso Dreyfus. Nesse sentido, podemos afirmar que o "realismo" adquire um ar de irrealidade para o leitor. No entanto, quando analisamos mais profundamente como as personagens são inseridas nos acontecimentos, percebemos que a guerra constitui um meio de apresentar os mesmos caracteres encontrados ao longo do romance em outras circunstâncias, o que permite ao narrador demonstrar como, apesar da diversidade e das transformações, os indivíduos permanecem os mesmos, suas características confirmam aquela "essência geral" e/ou comum de leis psicológicas radiografadas anteriormente.

Em segundo lugar, a confirmação de uma essência perceptível a um observador diferenciado, menos ingênuo, coloca a questão da narrativa através das personagens (o que conduz a refletir a respeito do dizer), mas, simultaneamente, através da sensibilidade com a qual se narra a situação de uma cidade em tempos de guerra.

À realidade extremamente cruel da guerra, o texto opõe um clima de sonho, invertendo o real que assume uma ambiência de irreal: são inúmeros os momentos em que as metáforas provocam admiração pela beleza das imagens, tão diferentes daquelas que uma cidade ameaçada poderia provocar, tão longínquas em função da impropriedade até geográfica (por exemplo: o céu da cidade comparado ao $\operatorname{mar}^{19}$ ), em que se cita as Mil e uma noites, ${ }^{20}$ evocada em função do clima de aventura e descoberta, no qual a atmosfera mantém "[...] dans cette nuit paisible et menacée, gardait une apparence de rêve, de conte [...]", e uma atitude de herói de romance: “[...] et c'est à la fois avec une fierté de justicier et une volupté de poète que j'entrai délibérément dans l'hotel." 21

Quase todas as personagens principais do romance são revisitadas no contexto da guerra, configurando um re-arranjo da perspectiva, seja por reafirmação, seja por oposição que reafirma o que foram. Assim, aparentemente desligada da leitura e da escrita, encontramos uma reflexão sobre a expressão de um sentimento em palavras. No tempo da guerra, que se situa entre a estadia em Combray e a derradeira recepção, o herói volta a Paris e encontra os amigos: Bloch, representante do judeu vulgar, "pleutre et fanfaron" ("pelintra e fanfarrão") ${ }^{22}$, Saint-Loup, representante do "héroïsme inexprimé" ("heroísmo inexpresso"), imbuído de "[...] une espèce de délicatesse morale que empêche d'exprimer les sentiments trop profonds [...]", ${ }^{23}$ delicadeza que é também uma forma de "[...] qualité en quelque sorte morale de son intelligence." (“[...] qualidade de certa forma moral de sua inteligência."). ${ }^{24}$

A personagem Saint-Loup encarna uma maneira verdadeiramente nobre de interpretar a guerra, tornando-se contraponto dos artigos de jornal que o narrador comenta, o oposto do nacionalismo vulgar, embrutecedor da sensibilidade, representado por Bloch. O que a personagem Saint-Loup oculta é outra sensibilidade possível, muito mais comovente para o herói justamente porque não se exibe. Nesse sentido, é significativo que a personagem do amigo reencontrado agora na sua faceta mais luminosa seja comparada à mãe do herói na sua abnegação incapaz de se gabar de um sentimento, mas absolutamente autêntica nas ações provocadas por ele.

Cadernos Benjaminianos, Número especial, Belo Horizonte, 2013, página 100-114 105 
O caráter de Saint-Loup, que une sensibilidade e inteligência, provoca uma reação por um ângulo inesperado para o leitor ingênuo: "[...] par habileté artistique qui fait naître l'emotion en la dissimulant." 25 As cartas que o amigo envia do front, são comparadas às dos heróis que descrevem a guerra a partir de uma estética vulgar, se utilizando de expressões medíocres e lugares-comuns:

[...] Saint-Loup, lui, beaucoup plus intelligent et artiste, restait intelligent et artiste, et notait avec goût pour moi des paysages, pendant qu'il était immobilisé à la lisière d'une forêt marécageuse, mais comme si c'avait été pour une chasse au canard. ${ }^{26}$

A aparente frieza dessa descrição oculta um caráter generoso e desinteressado, capaz de perceber beleza mesmo nos momentos mais trágicos, o que dá o tom da reflexão sobre a guerra, onde os mais corajosos são os menos falantes. A notícia da morte deste amigo no front provoca pensamentos melancólicos: a amizade que, paradoxalmente, tinha sido desvalorizada e vivida de um modo superficial, perante a possibilidade de não poder usufruí-la mais, adquire a dimensão retrospectiva de uma amizade silenciosa nas pequenas atenções, pelas lembranças em circunstâncias diferentes ao longo da vida, nas quais o que permanece é a essência delicada do amigo.

Pode-se observar, na caracterização de Saint-Loup, um paralelo entre o caráter íntegro e uma percepção de artista que despreza o sucesso ruidoso; portanto, vislumbramos que as reflexões em torno desta personagem ilustram o valor do silêncio e da solidão. Nesse sentido, apresenta-as como necessárias ao trabalho artístico: a solidão que provém do afastamento do mundo social e o silêncio que se instaura pelo isolamento em relação às relações mundanas, ambas imprescindíveis para empreender a obra.

Destacando o heroísmo silencioso de Saint-Loup, o herói identifica-se com o amigo também no desprezo que ambos sentem por aqueles que tentam passar por gênios dando nomes pomposos às teorias que apresentam. ${ }^{27}$ Encontramos o mesmo desprezo aliado à questão da boa ação na teoria estética apresentada no final, no contexto da redescoberta da possibilidade da obra: “[...] la bonne action pure et simple, qui ne dit rien. L'art véritable n'a que faire de tant proclamations et s'accomplit dans le silence." 28

É significativo que a necessidade do silêncio seja colocada no cerne da questão da amizade. $\mathrm{O}$ amigo admirado pela delicadeza silenciosa é como a integridade moral que dispensa palavras. No entanto, contraditoriamente, a amizade é uma simulação (simulation $^{29}$, como tudo aquilo que ilusoriamente acreditamos ser real. É que a amizade, como o amor, como os prazeres mundanos, como a satisfação dos desejos, como a beleza dos lugares e dos objetos nunca é fruída na presença, mas na ausência.

No final, descoberta a possibilidade da obra, constata-se "[...] l'impossibilité d'atteindre dans la réalité ce qui était au fond de moi-même [...]". ${ }^{30}$ Porque só a imaginação, que cria os desejos e a inteligência, que na lembrança os revela, podem reconstituir o que somente se pode usufruir na solidão. Por isso, o afastamento das relações e obrigações sociais é colocado como atitude necessária para perscrutar, o que provoca um afastamento das pessoas para vê-las mais nitidamente.

Novamente, é a decepção com a realidade banal que conduz a uma "verdade nova", distante do gozo imediato, a autenticidade da vida "fora da ação", assumindo

Cadernos Benjaminianos, Número especial, Belo Horizonte, 2013, página 100-114 106 
“[...] l'impuissance que nous avons à nous réaliser dans la jouissance matérielle, dans l'action effective." ${ }^{, 31}$ A verdade nova consiste em transformar essa incapacidade em sentido, ela é, simultaneamente, a ação malograda e a verdade atingida, por isso, precisa ser traduzida. Configura-se assim a necessidade de ausência, de uma espécie de afastamento que possa re-viver o vivido na solidão que o reconstrói para permitir senti-lo verdadeiramente. A solidão propicia o usufruto da vida, a condição de que ela não viva, mas reencontre o vivido.

\section{O sentido e a memória}

A realidade insípida do presente situa-se no malogro da realização do desejo que, mesmo quando satisfeito, apresenta-se muito aquém do imaginado. No esgotamento do prazer e da satisfação instaura-se a procura da verdade do vivido. O ressurgimento de um momento em que se pode usufruir o passado no presente, na memória involuntária, é diferente do que o narrador denomina "souvenirs sans vérité" ("lembranças sem verdade"), ${ }^{32}$ próprias da memória voluntária ou do esforço da inteligência abstrata.

Mais qu'un bruit, qu'un odeur, déjà entendu ou respirée jadis, le soient de nouveau, à la fois dans le présent et dans le passé, réels sans être actuels, idéaux sans être abstraits, aussitôt l'essence permanente et habituellement cachée des choses se trouve libérée, et notre vrai moi qui, parfois depuis longemps, semblait mort, mais ne l'était pas entièrement, s'éveille, s'anime en recevant la céleste nourriture qui lui est apportée. ${ }^{33}$

A impressão reencontrada desencadeia imagens que precisam ser decifradas espiritualmente, descobrindo seu sentido. Assim, não é somente a memória involuntária, o acaso de uma sensação que traz o passado para o presente, mas a essência comum aos seres, às coisas, às situações, que deve ser recriada como verdade apreendida e elaborada a partir de idéias como sucedâneos desses momentos, o que torna a vida espiritual mais verdadeira. Nesse sentido, os momentos da memória involuntária propiciam o retorno de mundos inteiros, mundos que podem ser recriados pelo espírito em uma obra de arte.

No contexto do resgate da infância perdida em Combray, a reflexão sobre a arte e a verdadeira literatura transforma-se em uma discussão sobre o realismo. O narrador demonstra a falsidade da arte considerada realista. No momento em que acontecimentos históricos tão relevantes, como o caso Dreyfus ou a guerra, provocam nos críticos imbuídos do espírito da época a exigência de uma literatura à altura da seriedade da vida, que apresente a realidade com seus heróis e intelectuais preocupados em pensar os acontecimentos, o estilo é um luxo desnecessário. No entanto, a preferência por uma "visão cinematográfica" ${ }^{34}$ da vida própria dessa visão realista, não consegue atingir as profundezas de uma percepção verdadeira.

É no âmbito desta reflexão que reencontramos o sentido perdido da literatura, significativamente, logo após uma longa explicitação sobre a memória involuntária, provocada pelo acaso que o faz reencontrar o romance de G. Sand que sua mãe tinha lido no momento indelével daquela noite já citada, cujo sentido não cessa de ser redescoberto.

Cadernos Benjaminianos, Número especial, Belo Horizonte, 2013, página 100-114 107 
C'était une impression bien ancienne, où mes souvenirs d'enfance et de famille étaient tendrement mêlés et que je n'avais pas reconnue tout de suite. Je m'étais au premier instant demandé avec colère quel était l'étranger qui venait me faire mal. Cet étranger, c'était moi-même, c'était l'enfant que j'étais alors, que le livre venait de susciter en moi [...] et voici que mille riens de Combray, et que je n'apercevais plus depuis longtemps, sautaient légèrement d'eux-mêmes et venaient à la queue leu leu se suspendre au bec aimanté, en une chaîne interminable et tremblante de souvenirs. ${ }^{35}$

$\mathrm{Na}$ solidão da sala de espera da recepção derradeira, é toda a vivência de Combray que surge e, com ela, todo o sentido misterioso da literatura que propicia a descoberta dos mundos. Em que consiste esse mistério já vislumbrado em Combray, reencontrado agora, no momento em que parecia perdido?

Parece-nos que se apresenta na possibilidade de transcender as primeiras vivências de satisfação perdidas, em sublimar a dor e a tristeza da perda desse estrangeiro que descobre ser ele mesmo, criando um outro tempo que propicia a junção dos momentos através da literatura. As coisas, como as sensações, propiciam a retomada do contexto que configurava o eu antigo e o universo ao qual pertencia.

Assim, a literatura realista que se limita à descrição de objetos ou acontecimentos é a que menos capta a realidade, uma vez que a verdadeira essência das coisas está na comunicação com os eus que fornecem os sentidos, eus que modificam a sensibilidade de acordo com sensações que possibilitem trazer experiências anteriores ao presente para serem re-vividas, em outras palavras, autenticamente vividas. Essa experiência é subjetiva e, no limite, incomunicável ${ }^{36}$ no entanto, delineia a tarefa do escritor, na medida em que sua tentativa deve constituir a tradução das relações entre sensações e lembranças que formam a verdadeira realidade.

Une heure n'est pas qu'une heure, c'est un vase rempli de parfums, de sons, de projets et de climats. Ce que nous appelons la réalité est un certain rapport entre ces sensations et ces souvenirs qui nous entourent simultanément - rapport que supprime une simple vision cinématographique, laquelle s'eloigne par là d'autant plus du vrai qu'elle se borner à lui - rapport unique que l'écrivain doit retrouver pour en enchaîner à jamais dans sa phrase les deux termes différents. ${ }^{37}$

Abre-se uma realidade complexa, que reúne objetos e situações associados de uma maneira única, uma circunstância singular, impossível de ser recriada voluntariamente. Somente através da obra na singularidade de cada artista é que esses mundos podem ser traduzidos em um estilo que possa harmonizar todo esse feixe de relações de modo a lhes dar um sentido. O estilo é constituído pela subjetividade de cada artista, único na possibilidade de traduzir seu mundo específico. Paradoxalmente, o artista universaliza seu mundo particular traduzindo-o de maneira que possibilite a compreensão dos outros. O meio mais conveniente para essa tradução é a metáfora porque pode aproximar sensações diversas outorgandolhes uma essência comum.

Compreende-se, assim, que a arte realista não possua beleza, pois ela oculta a verdadeira realidade que o artista desvendará através de uma visão diferenciada da

Cadernos Benjaminianos, Número especial, Belo Horizonte, 2013, página 100-114 108 
convencional, uma visão que devasse profundezas além da mera inteligência. Esta visão constitui-se na "penumbra que atravessamos"38 em nós mesmos, travessia que redescobre à sua maneira mundos possíveis. As expressões inexatas, os clichês, a convenção enfim, afastam-nos da vida plena.

Notre vie; et aussi la vie des autres; car le style pour l'écrivain aussi bien que la couleur pour le peintre est une question non de technique mais de vision. Il est la révélation, qui serait imposible par des moyens directs et conscients, de la différence qualitative qu'il y a dans la façon dont nous apparaît le monde, différence qui, s'il n'y avait pas l'art, resterait le secret éternel de chacun. ${ }^{39}$

A decifração da vida verdadeira requer o trabalho de desfazer as ilusões ligadas à paixão, ao hábito, à inteligência abstrata, para, posteriormente, através do sofrimento, retomar a reflexão e a elaboração necessárias à universalização da sensação e do sentimento, resgatando um conjunto de verdades que compõem a obra e que oferecerão ao leitor a possibilidade de conhecer um mundo e, concomitantemente, de se reconhecer nele. Unicamente o artista que sabe se tornar espelho para os outros, aquele que consegue refletir sua vida de modo a permitir que o leitor se veja nele, que reconheça as características das leis gerais e comuns ao humano, somente esse artista oferece a possibilidade da leitura de si mesmo, porque desvendando os sentimentos e as paixões singulares, desvenda o que é comum a todos.

Numa carta a Daniel Halévy, datada de 19 de julho de 1919, Proust afirma o que constitui a essência mesma dessa problemática: “[...] que c'est à la cime même du particulier qu'éclôt le général". ${ }^{40}$ Do mesmo modo que o herói adquire conhecimento dos mecanismos de seu desejo na fruição teatral e reconhece em Fedra sentimentos que ele mesmo não sabia que iria vivenciar, assim como a personagem Swann se comunica com a música de Vinteuil, todas as grandes obras constituem uma maneira de sair e de voltar a si que possibilita várias dimensões de autocompreensão.

Assim, o estilo não é uma questão de técnica, mas se constrói como visão na medida em que traduz o trabalho necessário para decifrar a impressão intransferível de seu mundo; sua tarefa consiste em comunicar essa visão desde seu interior, transformando o exterior a partir de sua perspectiva, diferente em cada um. No contexto de toda esta reflexão estética, a obra termina pelo anúncio de seu começo, a falta de talento transmuta-se na constatação de que há outra visão possível, a preguiça transforma-se em urgência de empreender o trabalho.

\section{Para não concluir}

O fim se nos apresenta de modo problemático a partir de duas questões intrinsecamente ligadas. Em primeiro lugar, se considerarmos que o próprio narrador nos adverte do perigo de colocar etiquetas, afirmando também que as verdadeiras obras se produzem no silêncio e na escuridão, poderemos suspeitar que a eternidade proclamada na obra de arte não é mais que o tempo constantemente retomado. $\mathrm{O}$ "homem eterno" "41 que desfruta fragmentos de existência fora do tempo sabe que a contemplação que os torna possíveis pertence à eternidade, embora de maneira fugaz. ${ }^{42}$

Cadernos Benjaminianos, Número especial, Belo Horizonte, 2013, página 100-114 109 
Em segundo lugar, a circularidade atingida na constatação de que a obra termina quando se anuncia seu começo, aponta para a problematicidade do próprio tempo na relação literatura e vida, na medida em que esta adquire sentido pela obra. Se a literatura não consiste num jogo diletante, nem na simples descrição da realidade, nem na expressão equivocada de sentimentos, tampouco se constitui de um material ideal abstrato formado por grandes assuntos metafísicos.

Parece-nos que é justamente no movimento dialético de oposição entre vida e literatura, nesse ir e vir da impressão para sua expressão, que atingimos a verdadeira vida, que não constitui simples vida ou simples expressão, mas que é propiciada pelo jogo de forças da relação entre as duas, que torna possível a obra. Nesse jogo, a verdade somente pode ser provisória, na medida em que o movimento dialético que nega um dos lados volta a produzir sua diferença sucessivamente, tornando a obra necessariamente inacabada. Neste sentido, há uma materialidade que insiste em permanecer, embora ela possa ser transfigurada em arte, é possível perceber que não desaparece e que constitui a densidade vital que se tornará expressão. Na passagem da impressão para sua expressão o jogo de forças é passível de se multiplicar em várias direções.

Assim, é preciso problematizar o próprio sentido da verdade atingida que a obra desmente. O caráter desse desmentido é propiciado pela mutabilidade, pela incerteza desse eu que se desdobra em muitos, morrendo e renascendo na própria narrativa a partir da concomitância de mundos diferentes, que, como camadas de experiência, são acrescidos, esquecidos e retomados de muitas maneiras. Aparentemente, a obra coloca em questão a visão realista do real em função de uma visão que, pelo jogo do tempo, alcançaria uma verdade extratemporal. No entanto, qual é o critério que garantiria que este último eu, que descobre o sentido da vida na obra de arte, não seria mais um na longa fileira de eus carregados ao longo da vida do herói? Poderia ser a pintura de mais um erro que não conduz à verdade?

O que precisaria ser discutido, então, é se o eu atingido poderia garantir a unidade da fragmentação dos eus apresentados. Se, por um lado, afirma-se que o verdadeiro eu que renasce nesta experiência não tem receio em relação à morte: “[...] situé hors du temps, que pourrait-il craindre de l'avenir?"; ${ }^{43}$ por outro lado, a temporalidade possibilita a experiência de um eu outro, que, por sua vez, propiciará a experiência do verdadeiro eu.

Que je revoie une chose d'un autre temps, c'est un jeune homme que se lèvera. Et ma personne d'aujourd'hui n'est qu'une carrière abandonnée, qui croit que tout ce qu'elle contient est pareil et monotone, mais d'où chaque souvenir, comme un sculpteur de génie tire des statues innombrables. ${ }^{44}$

Em função desses aspectos, podemos pensar o sentido da obra como não proclamado. Nas palavras de Benjamin num texto sobre Proust: "Nem sempre proclamamos em voz alta o que temos de mais importante a dizer." 45

Com efeito, se mudarmos de perspectiva, se interpretamos o último volume do romance - O tempo reencontrado - como a reflexão do narrador a respeito da descoberta de seu herói, estaríamos prontos para pensar em várias dimensões as relações de subjetividade que a obra de Proust nos coloca. Assim, apresenta-se a necessidade de pensar a questão da unidade na diversidade a partir da questão da subjetividade, o que nos conduz a uma reflexão sobre a (im)possibilidade de tradução de uma experiência da subjetividade, que se relaciona com o mundo de

Cadernos Benjaminianos, Número especial, Belo Horizonte, 2013, página 100-114 110 
formas múltiplas e não necessariamente lineares, que precisa se esfacelar para poder conter sua própria diversidade.

A verdade e o estilo dependem da experiência do eu, esse livro interior, mas de que eu se trata? Tal como é apresentada na obra, não é a verdade de algo que aconteceu, mas de como se passa em nós o que nos acontece, ou seja, a verdade da impressão reencontrada; essa experiência extrai um sem-número de eus, o que torna complexa a descoberta de seu significado. No entanto, a lembrança garante a fecundidade de uma obra que não cessa de colocar novos sentidos a serem perscrutados e traduzidos, infinitamente retomados pela escrita:

À partir d'um certain âge nos souvenirs sont tellement entre-croisés, les uns sur les autres que la chose à laquelle on pense, le livre qu'on lit n'a presque plus d'importance. On a mis de soi-même partout, tout est fécond, tout est dangereux, et on peut faire d'aussi précieuses découvertes que dans les Pensées de Pascal dans une réclame pour um savon. ${ }^{46}$

Resumen: Este estudio consiste en el análisis del sentido de la escritura en la novela de Proust, En busca del tiempo perdido, a partir del relato sobre la vocación, incluido en la trama de la novela. Presenta la duda a respecto del significado de la literatura en el contexto de la discusión sobre el realismo, lo que implica en la cuestión de la memoria como indispensable para entender la relación compleja entre la materialidad de la vida y la obra.

Palabras clave: literatura, recuerdo, vida

\section{Referências}

BENJAMIN, Walter. A imagem de Proust. In: Obras Escolhidas, Volume I. Trad. de Sérgio Paulo Rouanet e Prefácio de Jeanne Marie Gagnebin. São Paulo: Brasiliense, 1985 .

GAGNEBIN, Jeanne Marie. O rumor das distâncias atravessadas. In Remate de males. Campinas: IEL, UNICAMP.

PROUST, Marcel. À la recherche du temps perdu. 4 Tomes. Édition publiée sous la direction de Jean-Yves Tadié. Paris: Gallimard, 1987-1989.

PROUST, Marcel. Em busca do tempo perdido. 3 Volumes. Trad. Fernando Py, Rio de Janeiro: Ediouro, 2002.

Cadernos Benjaminianos, Número especial, Belo Horizonte, 2013, página 100-114 111 


\section{Notas}

${ }^{1}$ Nas notas, as referências à edição francesa são feitas pela sigla Recherche, aquelas à tradução em português, por Busca, de acordo com as edições citadas nas Referências bibliográficas. Recherche; Le temps retrouvé, v. 4, p. 474; Busca, v. 3, p. 683: "A grandeza da arte verdadeira ...”.

${ }^{2}$ Recherche, v. 4, p. 474; Busca, v. 3, p. 683: "A verdadeira vida ... é a literatura."

${ }^{3}$ PROUST, M. Le temps retrouvé, v. 4, Gallimard: Paris, 1989. No corpo do texto, utilizamos Recherche como abreviação do título original À la Recherche du temps perdu, em português: Em busca do tempo perdido.

${ }^{4}$ Recherche; Du côté de chez Swann, v. 1, p. 153; Busca, v. I, p. 133: “... discordância entre as nossas impressões e a sua expressão habitual."

${ }^{5}$ Recherche, v. 1, p. 153; Busca, v. 1, p. 133: "E vendo sobre a água e na superfície da parede um sorriso pálido responder ao sorriso do sol, gritei em meu entusiasmo, brandindo o guarda-chuva fechado: 'Oba! Oba! Oba!' Mas, ao mesmo tempo, senti que era meu dever não me contentar com essas palavras opacas e tentar ver mais claro em meu êxtase."

${ }^{6}$ Recherche, v. 1, p. 176; Busca, v. 1, p. 150: “... algo que me convidavam a vir pegar e que, apesar dos meus esforços, eu não conseguia descobrir." ${ }^{7}$ Ibidem.

${ }^{8}$ Recherche, v. 1, p. 179; Busca, v. 1, p. 152: "Sem dizer a mim mesmo que aquilo que se ocultava detrás das torres de Martinville devia ser algo semelhante a uma bela frase, pois que era principalmente sob a forma de palavras que me davam prazer, pedi lápis e papel ao doutor e, apesar dos ressaltos do carro, escrevi, para aliviar a consciência e obedecer ao meu entusiasmo, o fragmento seguinte..."

${ }^{9}$ Recherche; Le temps retrouvé, v. 4, 287; Busca, v. 3, p. 542.

${ }^{10}$ Recherche, v. 4, 301; Busca, v. 3, p. 553: “... uma magia ilusória da literatura, [...] esse lado mentiroso, essa falsa luz..."

${ }^{11}$ Recherche, v. 4, p. 297; Busca, v. 3, p. 550: “... verdade artística.”

${ }^{12}$ Recherche, v. 4, p. 297; Busca, v. 3, p. 550.

${ }^{13}$ Recherche, v. 4, p. 300; Busca, v. 3, p. 552: "Se tivesse compreendido, no passado, que não é o mais espirituoso, o mais instruído, o mais bem relacionado, mas aquele que sabe tornar-se espelho, para poder assim refletir a sua vida, embora acanhada, que chega a ser um Bergotte [...], teria observado que o mesmo sucede, e com mais razão, com os modelos do artista."

${ }^{14}$ Recherche; Le côté de chez Swann. v. 1, p. 182; Busca, v. 1, p. 154: "Mas é sobretudo como se pensasse em jazidas profundas do meu terreno mental, como nos solos resistentes em que ainda me apóio, que devo pensar no lado de Méséglise e no lado de Guermantes. E precisamente porque confiava nas coisas, nos seres que me fizeram conhecer, são os únicos que ainda levo a sério e ainda me dão alegria. Ou porque a fé que cria se haja esgotado em mim, ou porque a realidade só se forma na memória, as flores que hoje me mostram pela primeira vez não me parecem flores verdadeiras."

${ }^{15}$ Recherche, v. 1, p. 36-37; Busca, v. 1, p. 45: "A possibilidade de semelhantes horas nunca mais renascerá para mim. Porém, desde algum tempo recomeço a perceber muito bem, se apuro os ouvidos, os soluços que então consegui conter na presença de meu pai, e que só rebentaram quando fiquei a sós com mamãe. Na verdade, eles nunca cessaram; e é somente porque a vida se vai agora emudecendo cada vez mais a meu redor que os ouço de novo, como os sinos do convento que parecem tão silenciosos durante o dia por causa dos barulhos da cidade que os julgamos parados, mas que voltam a soar no silêncio da noite."

${ }^{16}$ GAGNEBIN, J. M. O rumor das distâncias atravessadas. In: Remate de Males. Campinas: IEL, Unicamp, 2002, v. 22, p. 120.

Cadernos Benjaminianos, Número especial, Belo Horizonte, 2013, página 100-114 112 
${ }^{17}$ Recherche; La prisonnière, v. 3, p. 549; Busca, v. 4, p. 296.

${ }^{18}$ Recherche, v. 3, p. 550; Busca, v. 4, p. 297.

${ }^{19}$ Recherche; Le temps retrouvé, v. 4, p. 341; Busca, v. 3, 584.

${ }^{20}$ Recherche, v. 4, p. 388; Busca, v. 3, p. 620.

${ }^{21}$ Recherche, v. 4, p. 391; Busca, v. 3, p. 622: “... nessa noite pacífica e ameaçada, uma aparência de sonho, de conto de fadas, e foi a um tempo com orgulho de justiceiro e volúpia de poeta que entrei deliberadamente no hotel."

${ }^{22}$ Recherche, v. 4, p. 319; Busca, v. 3, p. 567. Modificamos a tradução de pleutre para pelintra em lugar de covarde como faz a última tradução brasileira que estamos citando, por ser mais adequado ao contexto do sentido presunçoso que Proust deseja dar à imagem dessa personagem.

${ }^{23}$ Recherche, v. 4, p. 320; Busca, v. 3, p. 567: “... uma espécie de delicadeza moral que impede a expressão de sentimentos muito profundos..."

${ }^{24}$ Recherche, v. 4, p. 320; Busca, v. 3, p. 567.

${ }^{25}$ Recherche, v. 4, p. 323; Busca, v. 3, p. 570: “... pela habilidade artística que faz nascer a emoção dissimulando-a."

${ }^{26}$ Recherche, v. 4, p. 333; Busca, v. 3, p. 578: “... Saint-Loup, muito mais inteligente e artista, continuava sendo inteligente e artista, e fixava com finura, para mim, as paisagens que via enquanto estava imobilizado à beira de uma floresta pantanosa, mas como se participasse de uma caçada a patos selvagens."

${ }^{27}$ Cf. Recherche, v. 4, p. 320; Busca, v. 3, p. 568.

${ }^{28}$ Recherche, v. 4, p. 460; Busca, v. 3, p. 673: “... a boa ação pura e simples, que não precisa de palavras. A arte genuína se realiza em silêncio e não tende a fazer tantas proclamações."

${ }^{29}$ Cf. Recherche, v. 4, 454; Busca, v. 3, p. 668.

${ }^{30}$ Recherche, v. 4, p. 455; Busca, v. 3, p. 669: “... a impossibilidade de atingir, na realidade, aquilo que estava no fundo de mim mesmo."

${ }^{31}$ Recherche, v. 4, p. 455; Busca, v. 3, 669: “... nossa incapacidade de nos realizarmos no gozo material, na ação efetiva."

${ }^{32}$ Recherche, v. 4, p. 450; Busca, v. 3, p. 666.

${ }^{33}$ Recherche, v. 4, p. 450; Busca, v. 3, p. 666: "Mas desde que um ruído, um cheiro, já ouvido ou aspirado antes, o sejam de novo, ao mesmo tempo no presente e no passado, reais sem serem atuais, ideais sem serem abstratos, logo a essência permanente e em geral oculta das coisas se libera, e nosso verdadeiro eu, que às vezes parecia morto há muito tempo, mas não o estava de todo, desperta e se anima ao receber o alimento celeste que lhe trazem."

${ }^{34}$ Recherche, v. 4, p. 461; Busca, v. 3, p. 674.

${ }^{35}$ Recherche, v. 4, p. 462-463; Busca, v. 3, p. 675: "Era uma impressão bem antiga, em que minhas recordações da infância e da família se misturavam com ternura, e que eu não reconhecera de pronto. No primeiro instante, indagara a mim mesmo, encolerizado, quem era o estranho que vinha me fazer mal. Esse estranho era eu próprio, era a criança que eu fora àquela época, e que o livro acabava de suscitar em mim [...] e eis que mil nadas de Combray, há muito tempo olvidados, punham-se a saltar rapidamente por si mesmos, um a um, e vinham ligar-se ao bico imantado numa corrente interminável e trêmula de recordações."

${ }^{36}$ Cf. Recherche, v. 4, p. 464; Busca, v. 3, p. 676.

${ }^{37}$ Recherche, v. 4, p. 467-468; Busca, v. 3, p. 679: "Uma hora não é somente uma hora, é um jarro cheio de perfumes, de sons, de projetos e de climas. O que denominamos realidade é uma certa relação existente entre tais sensações e lembranças que nos cercam simultaneamente- relação que uma simples visão cinematográfica suprime, pois se afasta tanto mais da realidade quanto mais pretende limitar-se a ela- relação única que o escritor deve reencontrar para ligar-lhe para sempre em sua frase os dois termos diferentes."

Cadernos Benjaminianos, Número especial, Belo Horizonte, 2013, página 100-114 113 
${ }^{38}$ Recherche, v. 4 476; Busca, v. 3, p. 685.

${ }^{39}$ Recherche, v. 4, p. 474; Busca, v. 3, p. 683: "Nossa vida; e também a vida alheia; pois o estilo, para o escritor, tanto quanto a cor para quem pinta, é uma questão não de técnica, mas de visão. É a revelação impossível pelos meios diretos e conscientes, da diferença qualitativa que existe na maneira como nos surge o mundo, diferença que, se não houvesse a arte, ficaria sendo o segredo eterno de cada um."

${ }^{40}$ PROUST, M, Lettres. Paris: Plon, 2004, p. 911.

${ }^{41}$ Recherche; Le temps retrouvé. v. 4, p. 497; Busca, v. 3, p. 700.

${ }^{42}$ Cf. Recherche, v. 4, p. 454, v. 3, 668.

${ }^{43}$ Recherche, v. 4, p. 451; Busca, v. 3, p. 667: “... situado fora do tempo, o que poderia recear do futuro?"

${ }^{44}$ Recherche, v. 4, 464; Busca, v. 3, 667: "Revendo eu alguma coisa de outro tempo, outro rapaz se erguerá dentro de mim. E minha pessoa de hoje não passa de uma pedreira abandonada, a julgar que tudo aquilo que contém é igual e monótono, mas de onde cada lembrança, como um escultor de gênio, extrai um sem-número de estátuas."

${ }^{45}$ BENJAMIN, W. A imagem de Proust. In: BENJAMIN, Walter. Magia e técnica, arte e política: ensaios sobre literatura e história da cultura. Trad. Sérgio Paulo Rouanet, São Paulo: Brasiliense, 1985. - (Obras escolhidas; v. 1)

${ }^{46}$ PROUST, M. Recherche, v. 4, p. 124; Busca, v. 3, p. 408. "A partir de uma certa idade, as nossas lembranças ficam de tal modo entrecruzadas umas às outras, que a coisa em que pensamos, o livro que lemos, quase não tem importância nenhuma. Pusemos tanto de nós mesmos em toda parte, tudo é fecundo, tudo é perigoso, e também podemos fazer preciosas descobertas tanto nos Pensamentos de Pascal como num anúncio de sabonete.

Cadernos Benjaminianos, Número especial, Belo Horizonte, 2013, página 100-114 114 